\title{
Warranty of Misinforming: An Overview
}

\author{
Dimitar Christozov \\ American University in Bulgaria, Blagoevgrad, Bulgaria \\ dgc@aubg.bg \\ Stefanka Chukova \\ Victoria University of Wellington, New Zealand \\ stefanka.chukova@vuw.ac.nz \\ Plamen Mateev \\ Sofia University "St. Kliment Ohridski”, Sofia, Bulgaria \\ pmat@fmi.uni-sofia.bg
}

\begin{abstract}
In this paper we focus on models and methods for quantifying the risks related to a product purchase and the impact of product warranty on these risks. There are two risks associated with purchasing a product the risk of malfunctioning, i.e., the risk of buying a product that is not up to the quality prescribed by its specifications, and the risk of misinforming - the risk of buying a product that is not suitable for the tasks it is aimed for, i.e., misunderstanding the features of the product while deciding whether to buy it. The later risk is caused by the information asymmetry, which is a natural property of any communication process. Warranty is the usual sharing mechanism of these risks between the manufacturer/ vendor and clients. In this paper we review the ideas related to quantifying the risk of misinforming and discuss the role of the warranty of misinforming. We conclude our overview by outlining several possible directions for future research.
\end{abstract}

Keywords: warranty, misinforming, risk, information asymmetry.

\section{Introduction}

Nowadays trading is characterised by a rapid increase of the volume of indirect sales, which increases the volume of information exchanged between vendors and clients. Any potential problems in this exchange can affect the successful completion of the associated business transaction. Information failure occurs when people make their decisions based on imprecise, imperfect, unreliable or misunderstood data. In-

Material published as part of this publication, either on-line or in print, is copyrighted by the Informing Science Institute. Permission to make digital or paper copy of part or all of these works for personal or classroom use is granted without fee provided that the copies are not made or distributed for profit or commercial advantage AND that copies 1) bear this notice in full and 2) give the full citation on the first page. It is permissible to abstract these works so long as credit is given. To copy in all other cases or to republish or to post on a server or to redistribute to lists requires specific permission and payment of a fee. Contact Publisher@InformingScience.org to request redistribution permission. formation failure can occur in many different areas in our everyday life, not only while making a purchase decision, e.g., making decisions regarding investments, deciding on appropriate health insurance, borrowing and debt. In our everyday life we make decisions, based on received information that could turn out to be "wrong" due to information asymmetry. We often misunderstand the true costs/benefits of a product and end up buying a product that is not suitable for our needs. The same information 
asymmetry, or information imbalance, makes us uncertain on whether to buy an Apple or PC; what type of second hand car to buy; whether to buy a particular property or in which university to enroll?

The concept of asymmetric information originates in Arrow (1963), who introduced it as a "moral hazard". His ideas were further developed by Akerlof (1970) in his famous paper "The Market for 'Lemon's", where the term "information asymmetry" was used for the first time. There are many authors who followed Arrow and Akerlof and investigate different aspects of information asymmetry. In most of these studies, the information asymmetry was perceived as a tool used to gain some business advantages by exploring it intentionally. On the other hand information asymmetry may cause misunderstanding and mislead the recipient of information in his decision making even when the sender provides it in a good will, i.e., with a genuine intension of supplying a correct and complete information. To the best of our knowledge this point of view on the phenomenon of information asymmetry has received a limited attention of the researchers working in this area. Only few authors studied this aspect of information asymmetry, such as Hsieh, Lai, and Shi (2006), consider the impact of information asymmetry on the success in business transactions and observe that "information orientation framework" reduces the information asymmetry and improves company's performance. Manchanda, Xie, and Youn (2008) explore how information about adoption of new products is distributed via personal networks and allows potential adopters to learn from this experience. All of these studies do not go beyond recommendations on how to improve the process of informing. Others (see for example Katz, Berman, 2011) address the issue from point of view of contextualization, but also do not go beyond recommendations regarding improvement of the message quality via providing contextual information to compliment the original message. Internet based social networks also have the potential to provide contextual information aiming to reduce information asymmetry (see Christozov \& Toleva-Stoimenova, 2013).

In order to compensate for the information asymmetry hazards some risk sharing mechanisms between producers/vendors and consumers have been established, such as insurances, interest rates, and warranties. Product warranty affects the business transactions in two aspects (see Christozov, Chukova, \& Mateev, 2009a): firstly, by providing a legal frame of the deal, and secondly, by enhancing the trust between the parties involved. The two sources of risk that warranty contracts cover are:

- the risk of malfunctioning of the product, and

- the risk of making a wrong purchase decision while buying the product.

In general, "if the product fails - free of charge repair or replacement is provided" describes the first type of warranty, whereas the second type of warranty is summarized by the slogan "if not fully satisfied money back guaranteed". The warranty of malfunctioning is well studied and represented in the literature (see Blischke \& Murthy, 1993, 1996; Shafiee \& Chukova, 2013).

The warranty of misinforming is a relatively new topic in warranty analysis. In this paper we provide an overview of the existing models, approaches and algorithms for quantifying the risk of misinforming and the impact of misinforming hazards on product purchase decision making. The proposed misinforming measures provide an insight on the warranty cost and related warranty parameters and can be used for designing appropriate product warranty strategies.

The paper is organized as follows. Firstly we describe a communication process and its components as relevant to the problem of assessing the risk of misinforming. Next we provide a summary of the models for quantifying this risk, classified according to the available information. Further we review an approach that combines the two aspects of warranty - malfunctioning and misinforming. We conclude with a discussion on some open problems and future research directions related to warranty of misinforming.

\section{Assessment of the Risk of Misinforming}

Misinforming appears in any communication between two parties - say the sender and receiver. A simplified illustration of the process is given in Figure 1. Assume that the receiver faces a problem and needs 
some information to reduce the uncertainty in the problem solution. The sender has some knowledge / information potentially useful to the receiver in the problem domain. The sender formulates a message describing the meaning of that knowledge, encodes it and transmits it to the receiver. The receiver decodes the received message, understands and interprets it in terms of the problem and, if the information is found to be trustful and valuable, accepts it and adopts it in the problem solution. The misinforming is generated when the meaning of the message as formulated by the sender differs from the meaning of the message as adopted by the receiver.

Information asymmetry between a sender and receiver causes the misinforming - the sender formulates the message according to his background, knowledge, professional jargon etc., and the receiver understands the message according to his own background, knowledge and professional jargon and interprets the message in terms of the problem domain. So, we observe a two-sided asymmetry - the sender knows more than the receiver about the meaning of the message and the receiver knows more than the sender about the problem domain.

Information asymmetry is essential to any communication process. If there were no information asymmetry, i.e., none of the two parties is better informed on the subject, then there is no need of communication at all. Therefore there is a risk of misinforming in every communication process. So, for any communication process, the aim is to reduce the risk of misinforming and to assess the exposure to this risk, i.e., we wish to measure the likelihood of occurrence of misunderstanding during the communication process along with the impact of this misunderstanding on the receiver's behavior.

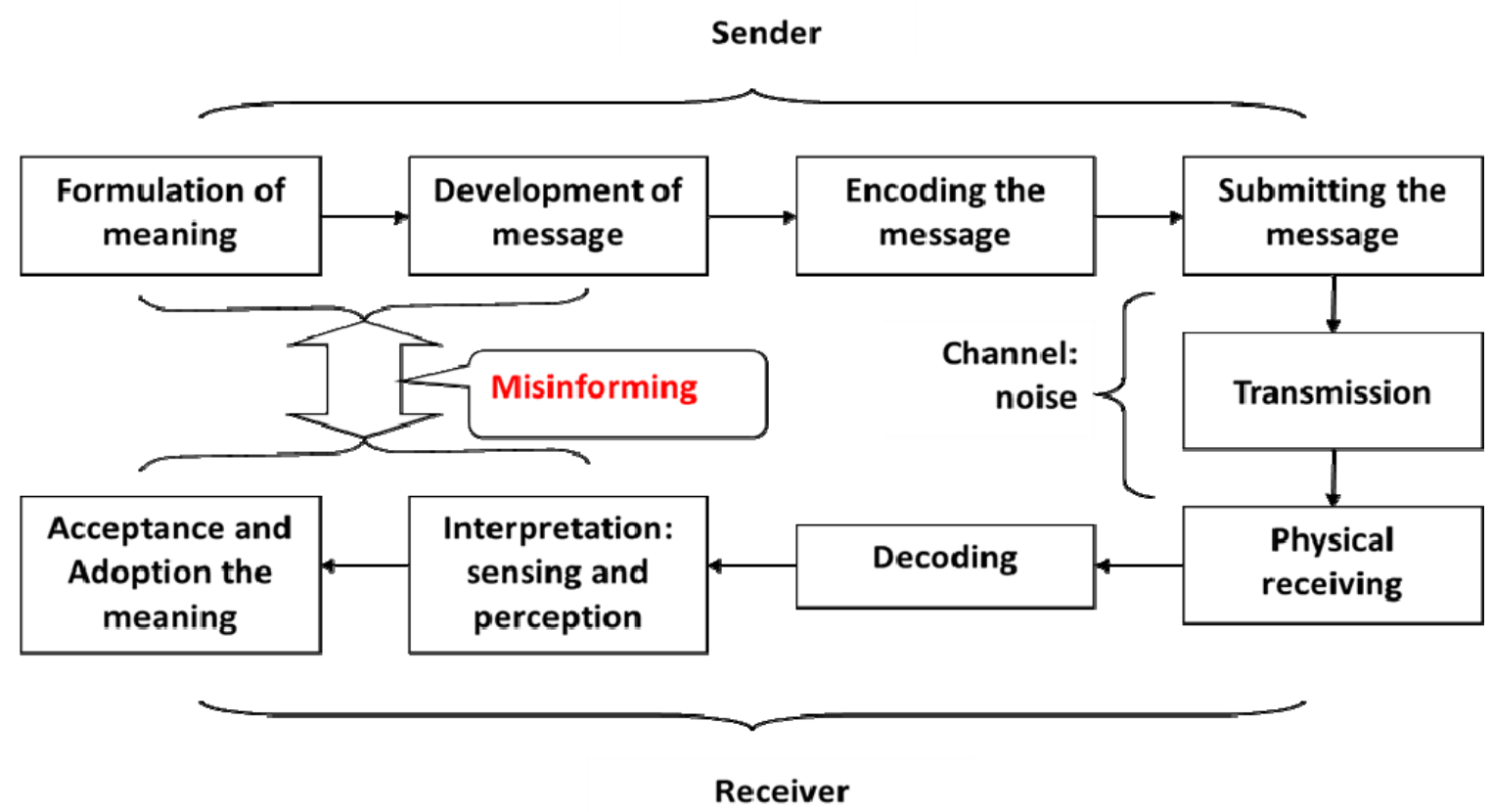

Figure 1. Stages in the communication process

To develop a measure of the risk of misinforming in purchase decision making, the following factors (see Figure 2.) have to be taken into account:

1. The parameters related to information asymmetry (the likelihood of the occurrence of misunderstanding):

a. The sender, while formulating the information message regarding the product, is not aware of the receiver's background/expertise and the problem he faces. For example, the sender is not aware of the tasks the receiver intends to perform, his needs in executing these tasks and the resources available for solving the problem. 
b. The receiver does not know well the relevance of the received information, its reliability, trustfulness and value.

2. Factors reducing the risk of misinforming such as:

a. opportunity to clarify the message - the existence of feedback

b. the trustfulness of the environment where the message was transmitted, e.g., buying goods from a shop in a mall compared to buying goods from a stall on the street.

c. risk sharing mechanism - e.g., product warranty.

3. Factors affecting the level (as an impact on receiver) of the risk of misinforming:

a. client's needs in executing a particular task using the product - a low level of needs results in a low impact of the misinforming on the receiver and therefore to a low risk exposure;

b. the acceptance level of the product - a low acceptance level means that almost every solution is acceptable, e.g., there are no strict requirements for the suitability of the product for the client's needs, and therefore related misinforming has a low impact on the client and his purchase decision making

In practice, quite often the receiver is not aware that he may misinterpret the received message and should consider options for controlling/reducing this risk.

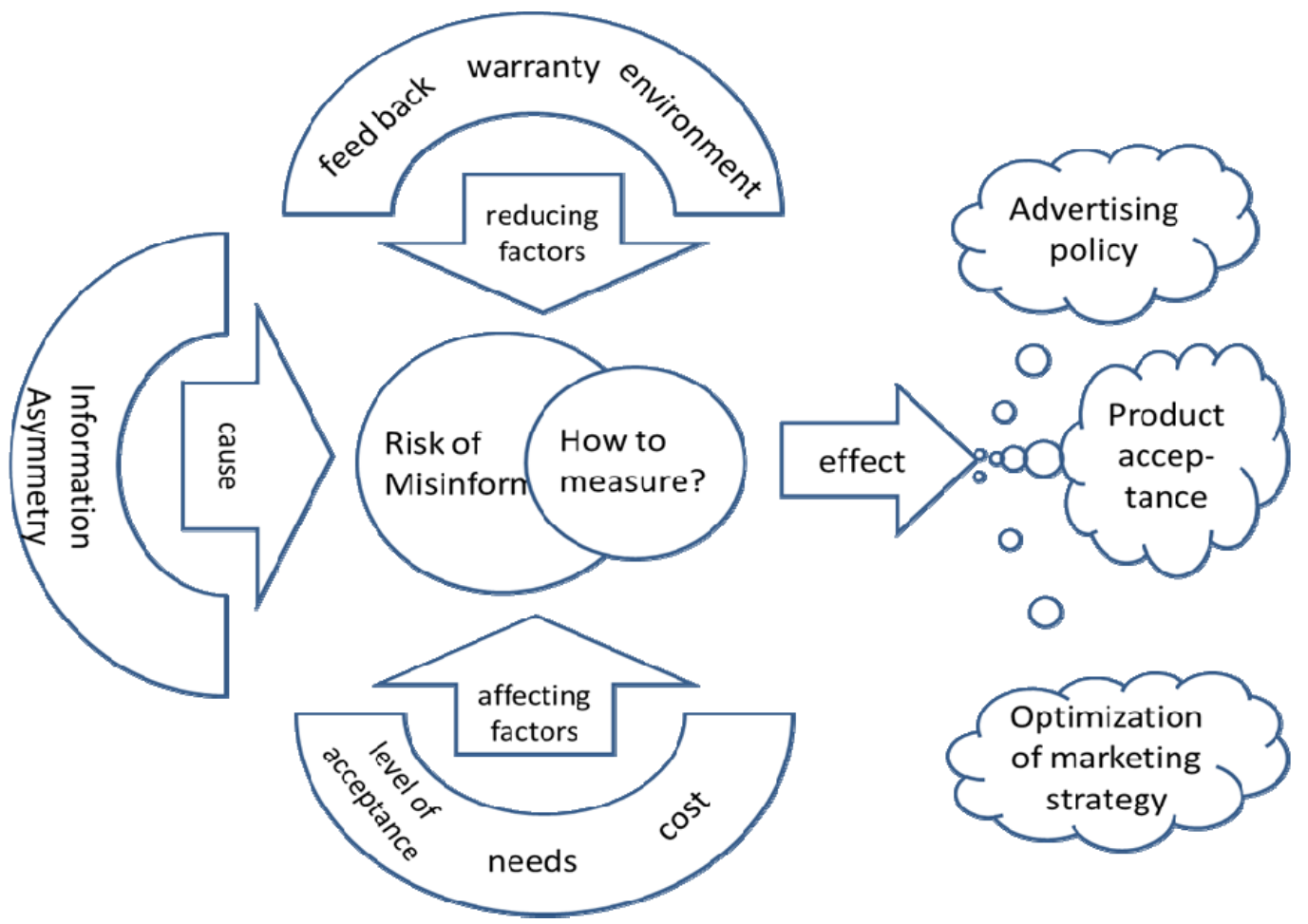

Figure 2. Risk of misinforming map

To model the risk of misinforming, we follow the framework developed in Christozov, Chukova, and Mateev (2009b). To illustrate the components that cause and affect the misinforming a simple communication process is used (see Figure 1). Firstly, these components have to be appropriately modelled to allow further quantification of the risk of misinforming. In brief, these components include:

A group of information clients, say $B=\left\{b_{j}\right\}, j=1,2, \ldots, J$, each in need of solving a given set of tasks, $A_{j}=\left\{a_{i j}\right\}, i=1,2, \ldots I_{j}$. Each of these tasks belongs to a given category of tasks $A=\left\{A_{i}^{*}\right\}, i=1,2, \ldots, I$, appropriately classified to utilize the information included in the sender's message. Every information client 
$b_{j}$ has a particular need $n_{i j}, 0 \leq n_{i j} \leq 1$ to solve his task from category $A_{i}^{*}$, with $n_{i j}=0$ indicating that this client does not need to solve any task from category $A_{i}^{*}$.

Assume that the group of clients receives a message, say a message $\boldsymbol{D}$, from the sender. The proposed measures for the quantification of the risk of misinforming are developed under the assumption that the sender's goal is to provide the clients with a correct, precise and complete information, i.e., his message reflects correctly, precisely and completely his understanding regarding of the category of problems $A$.

Further, let $C=\left\{c_{l}\right\}, l=1,2, \ldots L$ denotes the set of properties, attributes, parts, etc. of message $D$. Also, let $\left\{q_{j i l}\right\}, l=1,2, \ldots L$ are the personal levels of acceptance (thresholds) of client $b_{j}$ with respect to task $a_{i j}$ related to property $c_{l}$ of message $D$. The acceptance level of message $D$ for solving task

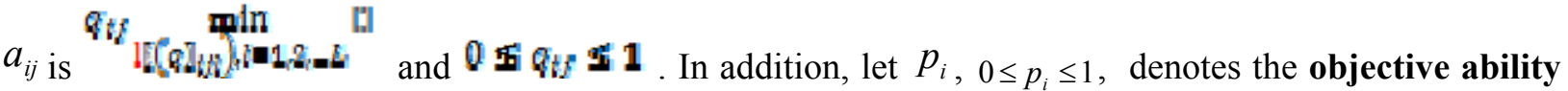
of the provided information to solve the tasks from category $A_{i}^{*}$, whereas $\hat{p}_{i j}, 0 \leq \hat{p}_{i j} \leq 1$, denotes $b_{j}{ }^{\prime} s$ subjective assessment that the provided information is useful in solving task $a_{i j}$. Also, let $r_{j i}$ be the decision indicator in using information $D$ for solving task $a_{i j}$, such that $r_{j i}=1$ indicates a wrong decision and $r_{j i}=0$ indicates a correct decision. There are six different orderings of the model parameters that affect the value of the decision indicator $r_{j i}$ :

$p_{i}<\hat{p}_{i j}<q_{i j}$ - the receiver's estimation is optimistic and below the degree of acceptance, thus the decision is negative and correct and $r_{i j}=0$;

$p_{i}<q_{i j}<\hat{p}_{i j}$ - the receiver's estimation is optimistic and above the threshold of acceptance, thus the decision is positive and wrong, and $r_{i j}=1$;

$q_{i j}<p_{i}<\hat{p}_{i j}$ - the receiver's estimation is optimistic and above the threshold of acceptance, thus the decision is positive and correct, and $r_{i j}=0$;

$\hat{p}_{i j}<p_{i}<q_{i j}$ - the receiver's estimation is pessimistic and below the threshold of acceptance, thus the decision is again negative and correct, and $r_{i j}=0$;

$\hat{p}_{i j}<q_{i j}<p_{i}$ - the receiver's is pessimistic and below the threshold of acceptance, thus the decision is negative and wrong, and $r_{i j}=1$;

$q_{i j}<\hat{p}_{i j}<p_{i}$ - the receiver's estimation is pessimistic and above the threshold of acceptance, thus the decision is positive and correct, and $r_{i j}=0$.

The level of error, caused by the information asymmetry (or the degree of information asymmetry), is measured by the difference between the real capability of the message to solve task $a_{i j}$ and how it is assessed by the receiver, i.e., $i a_{i j}=a b s\left(p_{i}-\hat{p}_{i j}\right)$. This is a measure of the likelihood for misunderstanding.

Some additional notations, needed to represent the measures of the risk of misinforming in the case of two competing messages, are provided in Appendix A. A complete list of the notations used in the models for quantifying the risk of misinforming and warranty of misinforming are summarized in Appendix B. 


\section{Measures of the Risk of Misinforming}

The model of communication process, presented earlier, describes several components that influence the risk of misinforming. According to available information on these components the models for quantifying the risk of misinforming could be classified as follows:

- M1 - Simple Model (known $r_{i j}$ ), which measures the risk of misinforming based only on the values of the decision indicators obtained via product warranty claims. It is assumed that the values of the decision indicators are always available.

- M2 - Model with known impact (known $r_{i j}$ and needs $n_{i j}$ ). This set of models quantifies the risk of misinforming, by taking into account the importance, from client's viewpoint, of solving a particular category of tasks. The information regarding the needs can be obtained via appropriately designed market studies.

- M3 - Model with known level of misunderstanding ( $\operatorname{known} r_{i j}$, needs $n_{i j}$ and $i a_{i j}$ ). This set of models utilizes additional information related to the information asymmetry. It is quite difficult to provide this additional information, because the assessment of the model parameters $p_{i}$ and $\hat{p}_{i j}$ is rather complex. So, their applicability in real life decision making is limited.

The above risk measures are designed in a way to distinguish the risks for the receivers and senders. Also these risk measures motivate a discussion on the role of product warranty in two different cases:

- static - making decisions for acquiring a tool/product to be used in solving the problem/the set of initially identified tasks;

- dynamic - utilizing the acquired tool and applying it in solving the problems/the set of initial tasks, which can be extended with a newly identified problems/tasks.

Also, the above models allow developing quantitative measures of the risk of misinforming in several communication scenarios:

- One-to-one: one message is send to one receiver. This is de-facto the risk of receiver.

- One-to-many: one message is distributed among multiple receivers. This is de-facto the risk of the sender and summarizes the risks of the group of receivers.

- Many-to-many: this is the case of competing messages (see Christozov, Chukova, Mateev, 2009c). The receivers have to choose the most suitable message for solving their tasks. A special case is the scenario of two competing messages, which allows for further generalization. The notations for this case are given in the Appendix 1.

In all of the above scenarios the measures of the risks of misinforming for the two parties, the senders and receivers, are developed. Table 1 provides a summary of these measures for the static case under different information availability levels and communication scenarios (see Christozov, Chukova, \& Mateev, 2009b). 


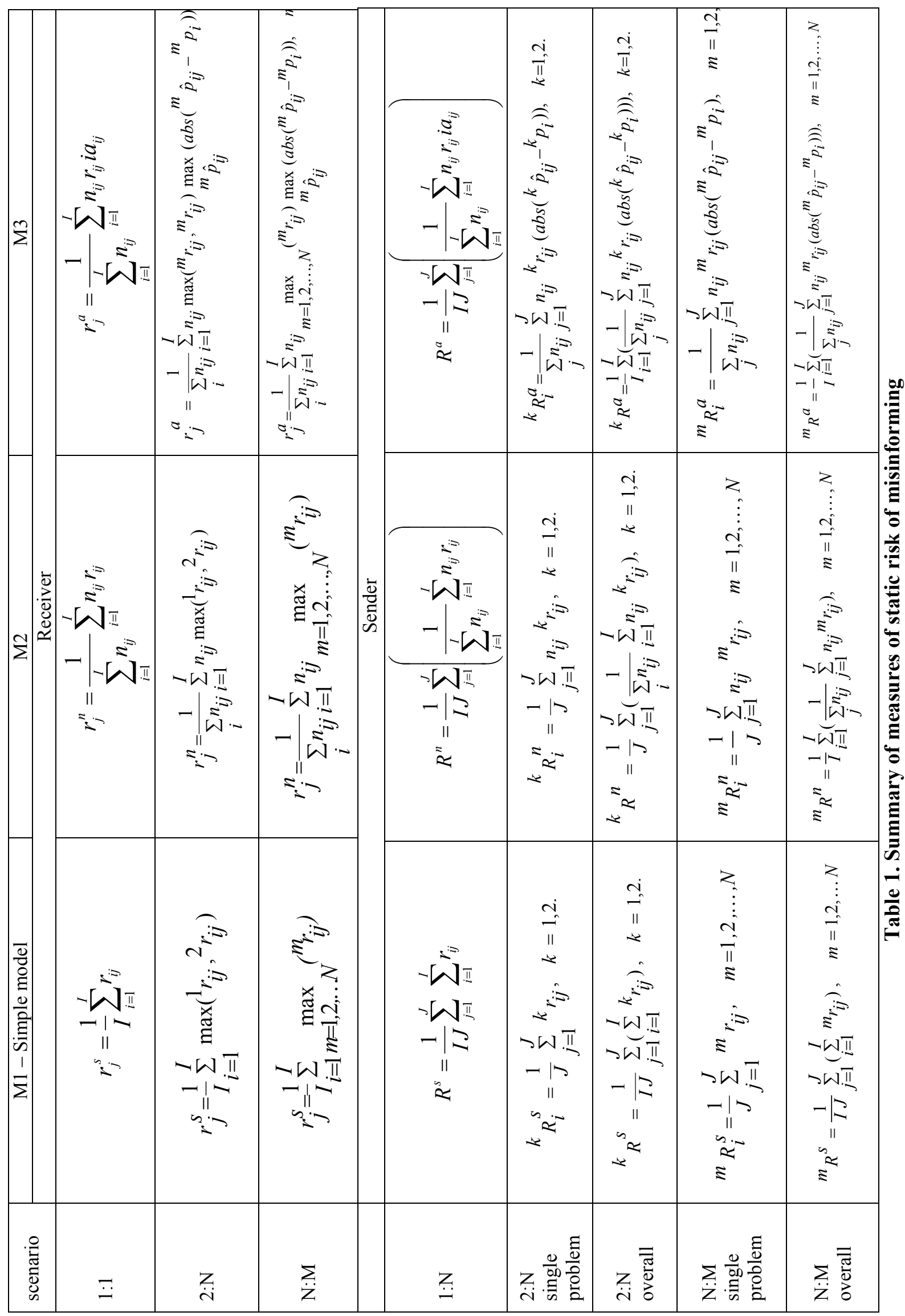


In the dynamic case (see Christozov, Chukova, \& Mateev, 2011), the warranty of misinforming affects the process of adoption and utilization of the meaning of the information message. Dynamic measures are justified by the fact that while using a given tool the client accumulates knowledge on its features and its suitability to solve the task, i.e.,

$$
\hat{p}_{i j}=\hat{p}_{i j}(t) \underset{t \rightarrow \infty}{\longrightarrow} p_{i} .
$$

So, how the measure of the risk of misinforming evolves during this process? In order to answer to this question a distinction between three groups of clients has to be introduced and their "wrong" decisions taken into account. The group of clients has to be split into three subgroups the subgroup of "optimists" who tend to overestimate the utility of the message, the subgroup of "pessimists" who tend to underestimate the utility of the message and the subgroup of "realists" who estimate the utility of the message quite well.

The evolution of the subjective assessment of the product's properties over time and gaining better understanding on what can be done with the product may result in client's dissatisfaction with the purchased decision made earlier. The optimists overestimate the utility and the learning curve $\hat{p}_{i j}(t)$ decreases in time and at a time $t$ may reach $q_{i j}\left(q_{i j}(t) \ll \hat{p}_{i j}(t)\right.$. The pessimists underestimate it and the curve $\hat{p}_{i j}(t)$ increases in time, but the $q_{i j}$ may increase faster and again $\phi_{i F}(t) \hat{R}_{i F}(t)$. In both cases the receiver may submit a warranty claim. The risk evolves over the time as follows:

$$
r_{i j}(t)=r_{i j}\left(p_{i}, \hat{p}_{i j}(t), q_{i j}(t) \mid t \leq t^{I}\right),
$$

where $t^{I}$ is the coverage for the warranty of misinforming. The dynamic measures for the risk of misinforming are summarized in Table 2, where $\mu_{i j}$ represents the importance of the warranty of misinforming $\left(0 \leq \mu_{i j} \leq 1\right)$ for receiver $b_{j}$ with respect to task $a_{i j}$.

\begin{tabular}{|l|c|c|}
\hline M1 & $r_{j}^{s}(t)=\frac{\sum_{i=1}^{k} r_{i j}(t)\left(\mu_{i j} t^{I}+\left(1-\mu_{i j}\right) t^{R}\right)}{\sum_{i=1}^{k} \mu_{i j} t^{I}+\left(1-\mu_{i j}\right) t^{R}}$ & $R^{s}(t)=\frac{\sum_{j=1}^{J} \sum_{i=1}^{k} r_{i j}(t)\left(\mu_{i j}^{a} t^{I}+\left(1-\mu_{i j}^{a}\right) t^{R}\right)}{\sum_{j=1}^{J} \sum_{i=1}^{k}\left(\mu_{i j}^{a} t^{I}+\left(1-\mu_{i j}^{a}\right) t^{R}\right)}$ \\
\hline M2 & $r_{j}^{n}(t)=\frac{\sum_{i=1}^{k} n_{i j}(t) r_{i j}(t)\left(\mu_{i j} t^{I}+\left(1-\mu_{i j}\right) t^{R}\right)}{\sum_{i=1}^{k} n_{i j}(t)\left(\mu_{i j} t^{I}+\left(1-\mu_{i j}\right) t^{R}\right)}$ & $R^{n}(t)=\frac{\sum_{j=1}^{J} \sum_{i=1}^{k} r_{i j}(t) n_{i j}(t)\left(\mu_{i j}^{a} t^{I}+\left(1-\mu_{i j}^{a}\right) t^{R}\right)}{\sum_{j=1}^{J} \sum_{i=1}^{k} n_{i j}(t)\left(\mu_{i j}^{a} t^{I}+\left(1-\mu_{i j}^{a}\right) t^{R}\right)}$ \\
\hline M3 & $r_{j}^{a}(t)=\frac{\sum_{i=1}^{k} n_{i j}(t) r_{i j}(t) i a_{i j}\left(\mu_{i j} t^{I}+\left(1-\mu_{i j}\right) t^{R}\right)}{\sum_{i=1}^{k} n_{i j}(t)\left(\mu_{i j} t^{I}+\left(1-\mu_{i j}\right) t^{R}\right)}$ & $R^{a}(t)=\frac{\sum_{j=1}^{J} \sum_{i=1}^{k} r_{i j}(t) n_{i j}(t) i a_{i j}\left(\mu_{i j}^{a} t^{I}+\left(1-\mu_{i j}^{a}\right) t^{R}\right)}{\sum_{j=1}^{J} \sum_{i=1}^{k} n_{i j}(t)\left(\mu_{i j}^{a} t^{I}+\left(1-\mu_{i j}^{a}\right) t^{R}\right)}$ \\
\hline
\end{tabular}

Table 2. Summary of measures of dynamic risk of misinforming 
The impact of warranty contracts on opportunity to learn for product's properties and client's needs is discussed in the next Section.

\section{Mixed Warranty Policy}

Next we review the concept of mixed warranty policy. The two types of warranty, the warranty of malfunctioning and warranty of misinforming have one main warranty parameter of interest - the warranty period. During this period of time, a warranty claim against a faulty/unsuitable product is legitimate. Next, we review (Christozov, Chukova, \& Mateev, 2010) to summarize, the so called, mixed warranty policy.

Definition 1. A warranty policy, $W_{p}=\left\{t^{R}, t^{I}\right\}$, is called a mixed warranty policy, if it accounts for the two types of warranties - the warranty of malfunctioning over $t^{R}=\left[0, t^{R}\right]$ and the warranty of misinforming over $t^{I}=\left[0, t^{I}\right]$.

The mixed warranty $W_{p}$ is identified by two ordered time periods, $t^{R}$ and $t^{I}$. This definition attempts to combine the warranty of malfunctioning and warranty of misinforming and propose a uniform mechanism for risk sharing for both - the uncertainty of malfunctioning as well as the uncertainty of misinforming. So, how to compare mixed warranty strategies, how to choose the "best" of these? In order to answer to these questions we need to discuss the notion of quality of warranty policy from producers' as well as from client's viewpoints.

Definition 2. From producers' point of view, the quality of a mixed warranty policy $W_{p}$, is identified by the expected warranty servicing cost and by the level of client's acceptance of the product.

Definition 3. From producers' point of view, a mixed warranty policy $W_{p}$ is of high (optimal) quality, if it minimizes the expected warranty servicing cost and it maximizes the level of product acceptance by the clients.

These definitions address the two major roles of warranty from seller's point of view. It serves as a sharing mechanism with the clients regarding the uncertainties of the product performance and promoting the product on the marketplace. Offering no warranty on malfunctioning will reduce the expected warranty cost to zero and will lead to a lower sale price, but at the same time will place the entire risk of malfunctioning or dissatisfaction on the client. Maximizing the level of acceptance of the product by allowing warranty returns for unlimited time is also unjustified policy from producers' point of view, because it could lead to substantial financial losses. A highquality warranty policy provides a balance between these two extremes, balance based on the evaluation of the risk of malfunctioning and the risk of misunderstanding.

Definition 4. From client's point of view, the quality of a mixed warranty policy $W_{p}$, is identified by the "balanced" value of the "warranty parameter" that provides the best support for the client's correct purchase decision and the level of uncertainty it allows in supporting client's correct purchase decision.

Definition 5. From client's point of view, a mixed warranty policy $W_{p}$ is of high (optimal) quality, if the "balanced" value of the "warranty parameter" is maximal and the level of uncertainty it allows in supporting client's correct purchase decision is minimal.

A possible approach on the selection of the "best" warranty periods $t^{R}$ and $t^{I}$ from producers' point of view is discussed in Christozov, Chukova, and Mateev (2010). To summarize, regarding 
the choice of the "best" $t^{I}$ our findings show that the parameter $t^{I}$ has to be selected according to the proportion of optimists in the clients' group, the level of their risk of misinforming, and the

level of corresponding information asymmetry. The second warranty parameter $t^{R}$ represents the warranty coverage related to malfunctioning of the product. It selection of its "best" value is based on the evaluation of the lengths of the following three (well-known in product reliability studies) sub-periods within the product's lifetime (see Christozov, Chukova., \& Mateev, 2010) the period of decreasing failure rate, the period of a normal performance (the, so called, useful lifetime of the product) and the period of increasing failure rate. The warranty period $t^{R}$ has to cover the period of decreasing failure rate and expire before the beginning of the increasing failure rate period. Due to the fact that the promotional strength of the warranty policy is proportional to the length of $t^{R}$, we aim to maximize $t^{R}$.

\section{Discussion}

Next we discuss the warranty of misinforming and its impact on the overall "wellbeing" of the manufacturer. There are several important reasons for the manufacturer to cover his products with warranty of misinforming along, of course, with the usual warranty of malfunctioning. For example:

- It is well know that even only one dissatisfied client has much higher negative impact on the producers' reputation compared the positive impact coming from many satisfied clients. For example, usually while selecting a product, say from Amazon.com, we read carefully all negative reviews, so we become aware of the drawbacks of the product. Often one strong, well-written negative review could affect our purchase decision. It is reassuring for the clients to see that the product is cover by warranty of misinforming in case that they have picked the "wrong" for their needs product. This warranty conveys the manufacturer willingness to share with the client the risk of "wrong" purchase decision and reinforces his firm standing by the strength and quality of his product.

- The warranty of misinforming has a positive impact on the sales process. It stimulates purchases of the product by clients that are uncertain in their ability to read the information message related to the product. Also, it contributes for a positive purchase decision of clients that are not entirely sure what they need the product for, i.e., they have not completely identified the set of their tasks $A_{j}=\left\{a_{i j}\right\}, i=1,2, \ldots I_{j}$.

- The finite warranty period $t^{I}$ of the warranty of misinforming protects the manufacturer from unreasonable claims related to products used for a long time. It provides a reasonable time to explore the features of the product and eliminates client dissatisfaction due to a possible misunderstanding of product capabilities, but prevents the misuse of warranty for unjustified free replacement or returns of the product for unlimited time period.

There are several possible new directions for extending the research on warranty of misinforming and related risk of misinforming summarized in this paper. For example:

- Formulating and solving an optimization problem for determining the "best" warranty period(s) under restricted budget. The formulation of this type of problems usually is based on manufacturer utility function along with the client utility function. Taking into account the information asymmetry, possible expressed through the risk of misinforming, will make the problem very realistic with a real value to the manufacturer in determining his best warranty strategy. The problem of optimizing the mixed warranty strategy is more involved and it might require the development of a measure of the joint warranty 
risk, to combine the two risks we discussed in this paper - the risk of malfunctioning and the risk of misinforming.

- As we already mentioned above, minimizing the client dissatisfaction is of high priority for the manufacturers, which we see through the numerous requests for a feedback on their product performance and product advertisement. The dissatisfaction from the product could be due to unappropriated or imprecise advertising message. Warranty models to include penalty function for client dissatisfaction will improve manufacturers advertising strategy and reduce the information asymmetry in the product description.

- Developing an approach on how to estimate the model parameters under M3, i.e., what type of data are needed for the estimations of the product suitability with respect to different tasks and how to collect such data.

- In the past two - three decades the volume of online purchases has increased dramatically. Due to the nature of this indirect business environment, the risk of misinforming shows upward trend. Therefore, developing additional tools/forms to promote/advertise the product "properly" becomes very important.

- As the risk of purchase dissatisfaction increases, the cost of warranty coverage also increases and prompts for more precise evaluation of the warranty contracts cost. Developing practical methodologies to evaluate the cost of warranty of misinforming, which will allow for "better" pricing, is still an open issue.

We have some initial ideas on how to approach the above problems and we will report our finding as we progress in our research.

\section{Conclusion}

This paper provides an overview of the models and approaches for the quantification of the risks associated with misinforming. Also, it includes some recent research ideas on the design of the warranty of misinforming, which addresses these risks. We believe that most of the results on the risk of misinforming and related warranties, summarized in this paper, are suitable for practical implementation.

Nowadays, the awareness of the role of information in companies' operation management is one of the major criteria in assessing companies' effectiveness. All inward and outward information flows regarding the company's production (or services) impact significantly the overall business performance. These flows are closely monitored by the information managers. Also, a rational attitude toward the warranty of misinforming, not only as a tool for promotion, but also as a product attribute that affects the overall business performance is necessary. This rational approach toward the warranty of misinforming will include the assessment of appropriate causeand-effect relationships, estimating related costs, cash flow planning, etc. Also, this rational attitude will require a systematic approach for collecting, processing and exploring data regarding the design and dissemination of the outward information and its impact on the receivers/customers, i.e., its interpretation and implementation in practice. Setting up such an information monitoring system can be considered, according to Gartner's EIM classification, as an indicator of moving from reactive to proactive stage of company's maturity. This type of information monitoring system is not a by-product of the "naturally" created and collected data within different departments of the company. Its design and implementation require launching special monitoring tools and development of special data processing procedures. 


\section{References}

Akerlof, G. A. (1970). The market for 'lemon's: Quality uncertainty and the market mechanism. Quarterly Journal of Economics, 84(3), 488-500.

Arrow, K. (1963). Uncertainty and the welfare economics of medical care. Cited in K. Arrow, Journal of Health Politics, Policy and Law,2001, 26, 851-883.

Blischke, W., \& Murthy, D. N. P. (1993). Warranty cost analysis. Marcel Dekker.

Blischke, W., \& Murthy, D. N. P. (1996). Product warranty handbook. Marcel Dekker.

Christozov, D., Chukova, S., \& Mateev, P. (2009a). On two types of warranties: Warranty of malfunctioning and warranty of misinforming. Asia-Pacific Journal on Operation Research, 26(3), 399-420.

Christozov, D., Chukova, S., \& Mateev P. (2009b). Chapter 11. Informing processes, risks, evaluation of the risk of misinforming. In T. G. Gill \& E. Cohen (Eds.), Foundations of Informing Science (pp. 323356). Santa Rosa, CA: Informing Science Institute.

Christozov, D., Chukova, S., \& Mateev, P. (2009c). The risk of misinforming for competing messages. Journal of Issues in Informing Science and Information Technology, 6, 351-364.

Christozov, D., Chukova, S., \& Mateev, P. (2010). Assessment of quality of warranty policy. Interdisciplinary Journal of Information, Knowledge, and Management, 5, 61-72. Retrieved from http://ijikm.org/Volume5/IJIKMv5p061-072Christozov447.pdf

Christozov, D., Chukova, S., \& Mateev, P. (2011). Assessment of risk of misinforming: Dynamic measures. Interdisciplinary Journal of Information, Knowledge, and Management, 6, 163-176. Retrieved from http://www.ijikm.org/Volume6/IJIKMv6p163-176Christozov550.pdf

Christozov, D., \& Toleva-Stoimenova, S. (2013). Knowledge diffusion via social networks: The 21st century challenge. International Journal of Digital Literacy and Digital Competence, 4(2), 1-12.

Hsieh, C. T., Lai, F., \& Shi, W. (2006). Information orientation and its impacts on information asymmetry and e-business adoption: evidence from China's international trading industry. Industrial Management \& Data Systems, 106(6), 825-840.

Katz, A., \& Berman, I. (2011). Designing an e-mail prototype to enhance effective communication and task management: A case study. Serdica Journal of Computing, 5(1), 39-64.

Manchanda, P., Xie, Y., \& Youn, N. (2008). The role of targeted communication and contagion in product adoption. Marketing Science, 27(3), 961-976.

Shafiee, M., \& Chukova, S. (2013). Maintenance models in warranty: A literature review. European Journal of Operations Research, 229(3), 561-572. 


\section{Appendix A. \\ Notation in the case of two competing messages $(2: \mathrm{N})$}

The client $b_{j}$ receives two competing messages ${ }^{1} D$ and ${ }^{2} D$ from two competing sources of information and $\mathrm{s} / \mathrm{he}$ has to choose the knowledge acquired only by one of them to solve her/his tasks or to ignore both. The client has the following options in making her/his decision:

1. choose ${ }^{1} D$ : this message is useful, the client solves her/his task $a_{i j}$, the decision is correct and the risk is ${ }^{1} r_{i j}=0$.

2. choose ${ }^{1} D$ : this message is not useful, the client doesn't solve her/his task $a_{i j}$, the decision is wrong and the risk is ${ }^{1} r_{i j}=1$.

3. choose ${ }^{2} D$ : this message is useful, the client solves her/his task $a_{i j}$, the decision is correct and the risk is ${ }^{2} r_{i j}=0$.

4. choose ${ }^{2} D$ : this message is not useful, the client doesn't solve her/his task $a_{i j}$, the decision is correct and the risk ${ }^{2} r_{i j}=1$

5. ignore both messages, but ${ }^{1} D$ is useful and client could have solved his task $a_{i j}$ if s/he has used the information from this message; while the message ${ }^{2} D$ doesn't bring any useful information. The decision is wrong and the risks are ${ }^{1} r_{i j}=1$ and ${ }^{2} r_{i j}=0$.

6. ignore both messages, but ${ }^{1} D$ is useful and the client could have solved his/her task $a_{i j}$ if $\mathrm{s} /$ he has used the information from this message; the message ${ }^{2} D$ also contains useful information. The decision is wrong and the risks are ${ }^{1} r_{i j}=1$ and ${ }^{2} r_{i j}=1$.

7. ignore both messages, but ${ }^{2} D$ is useful and client could have solved his/her task $a_{i j}$ if $\mathrm{s}$ /he has used the information from this message; while the message ${ }^{1} D$ doesn't bring any useful information. The decision is wrong and the risks are ${ }^{1} r_{i j}=0$ and ${ }^{2} r_{i j}=1$.

8. ignore both messages, and both message do not bring any useful information. The decision is correct and the risks are ${ }^{1} r_{i j}=0$ and ${ }^{2} r_{i j}=0$.

The client $b_{j}$ interprets each of the two messages according to her/his need and level of acceptance for a given task and according to her/his own assessment of how useful is the information received. ${ }^{1} p_{i}$ and ${ }^{2} p_{i}$ are the objective probabilities that each of the two messages is capable to solve category of tasks $A_{i}^{*} .{ }^{1} \hat{p}_{i j}$ and ${ }^{2} \hat{p}_{i j}$ the subjective probabilities, as assessed by the client $b_{j}$, regarding the capabilities of each of the two messages to solve her/his task $a_{i j}$. Regarding the task $a_{i j}$, the client $b_{j}$ has level of acceptance $q_{i j}$ and need $n_{i j}$. We assume that the client chooses to use the information from the message with higher ${ }^{*} \hat{p}_{i j}$, i.e., if ${ }^{1} \hat{p}_{i j}>{ }^{1} \hat{p}_{i j}$ s/he chooses to use ${ }^{1} D$ and vice versa. The risk of wrong decision is zero if the chosen option is correct, nevertheless that the alternative option is wrong. 


\section{Appendix B. \\ Notations and Definitions}

\begin{tabular}{|c|c|}
\hline Notation & Definition \\
\hline$D$ & the product \\
\hline$B=\left\{b_{j}\right\}, j=1,2, \ldots, n$ & the set of buyers \\
\hline$A_{j}=\left\{a_{i i j}\right\}, i=1,2, \ldots, k_{j}$ & tasks, which the $b_{i}$ needs to solve by using the product \\
\hline$A=\bigcup^{n} A_{j}$ & set of tasks of all buyers \\
\hline$A_{i}^{*}, i=1,2, \ldots, k$ & categories of tasks \\
\hline$n_{i j}$ & the need of $b_{j}$ to solve her task $a_{i j .} .0 \leq n_{i j} \leq 1$ \\
\hline$q_{i j}$ & $\begin{array}{l}\text { degree of acceptance. The minimal quality (a thresh- } \\
\text { old), which the product must possess in order to meet } \\
\text { the client } b_{j} \text { expectations regarding her task } a_{i j} \text {. }\end{array}$ \\
\hline$p_{i}=p\left(A_{i}^{*}\right)$ & $\begin{array}{l}\text { probability that the product will solve problems from } \\
\text { category } A_{i}^{*} \text {. Or the level to which the product } D \text { may } \\
\text { satisfy the buyers needs regarding the tasks from this } \\
\text { category }\end{array}$ \\
\hline$\hat{p}_{i j}=\hat{p}\left(a_{i j}\right)$ & $\begin{array}{l}\text { subjective assessment of the buyer } b_{j} \text { regarding the } \\
\text { probability (level of satisfaction) that the product will } \\
\text { be suitable for solving her task } a_{i j}\end{array}$ \\
\hline$r_{i j}$ & $\begin{array}{l}\text { indicator of the decision correctness } r_{i j}=0 \text { if the decison } \\
\text { is correct; } r_{i j}=1 \text { means wrong decision }\end{array}$ \\
\hline$i a_{i j}=\operatorname{abs}\left(p_{i}-\hat{p}_{i j}\right)$ & measure of information asymmetry \\
\hline$W_{p}(t)$ & warranty policy. $t$ - time of the coverage \\
\hline$W_{R}\left(t^{R}\right)$ & $\begin{array}{l}\text { warranty policy regarding risk of malfunctioning (risk } \\
\text { of low reliability) }\end{array}$ \\
\hline$W_{I}\left(t^{I}\right)$ & warranty policy regarding the risk of misinforming \\
\hline$W_{p}=\left\{t^{R}, t^{I}\right\}$ & mixed warranty policy, if $t^{R} \neq 0$ and $t^{I} \neq 0$ \\
\hline$W_{p}\left(t^{R}, 0\right)$ or $W_{p}\left(0, t^{I}\right)$ & pure warranty policies \\
\hline$\mu_{i j}, 0 \leq \mu_{i j} \leq 1$ & $\begin{array}{l}\text { subjective assessment of importance of the misinform- } \\
\text { ing warranty policy for making purchase decision by } b_{j} \\
\text { in respect to task } a_{i j} \text {. }\end{array}$ \\
\hline$B\left(W_{i j}\right)=\mu_{i j} t^{I}+\left(1-\mu_{i j}\right) t^{R}$ & $\begin{array}{l}\text { "balanced" value - represents the effective coverage of } \\
\text { a warranty policy }\end{array}$ \\
\hline$Q\left(W_{i j}\right)=\sqrt{\left(t^{I}-B\left(W_{i j}\right)\right)^{2} \mu_{i j} \cdot+\left(t^{R}-B\left(W_{i j}\right)\right)^{2} \cdot\left(1-\mu_{i j}\right)}$ & $\begin{array}{l}\text { standard deviation - represents the uncertainty associ- } \\
\text { ated with the warranty policy }\end{array}$ \\
\hline$r_{j}^{s}\left(r_{i j}\right)$ & $\begin{array}{l}\text { "simple" measure of the risk in a purchase decision for } \\
b_{j} \text {, depends only on whether the decision is correct or } \\
\text { not }\end{array}$ \\
\hline$r_{j}^{n}\left(r_{i j}, n_{i j}\right)$ & $\begin{array}{l}\text { measure of the risk in a purchase decision for } b_{b} \text {, de- } \\
\text { pends on whether the decision is correct or not; and the } \\
\text { needs }\end{array}$ \\
\hline
\end{tabular}




\begin{tabular}{|l|l|}
\hline$r_{j}^{a}\left(r_{i j}, n_{i j}, i a_{i j}\right)$ & $\begin{array}{l}\text { measure of the risk in a purchase decision for } b_{j}, \text { which } \\
\text { incorporates the indicator for correctness of the deci- } \\
\text { sion, the needs and the measure of information asym- } \\
\text { metry }\end{array}$ \\
\hline$R_{j}^{s}\left(r_{i j}\right)$ & $\begin{array}{l}\text { "simple" measure of the risk in a purchase decision for } \\
\text { group } B, \text { depends only on whether the decision is cor- } \\
\text { rect or not }\end{array}$ \\
\hline$R_{j}^{n}\left(r_{i j}, n_{i j}\right)$ & $\begin{array}{l}\text { Measure of the risk in a purchase decision for group } B, \\
\text { depends on whether the decision is correct or not; and } \\
\text { the needs }\end{array}$ \\
\hline$R_{j}^{a}\left(r_{i j}, n_{i j}, i a_{i j}\right)$ & $\begin{array}{l}\text { measure of the risk in a purchase decision for group } B, \\
\text { which incorporates the indicator for correctness of the } \\
\text { decision, the needs and the measure of information } \\
\text { asymmetry }\end{array}$ \\
\hline$r(t)$ and $R(t)$ & dynamic measures of the risk for $b_{j}$ and for group $B$ \\
\hline
\end{tabular}

\section{Biographies}

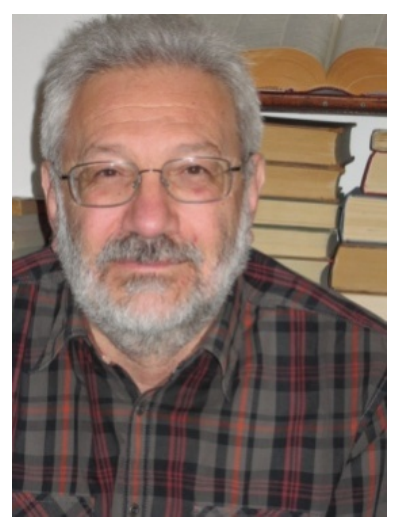

Dimitar Christozov is a Professor of Computer Science at the American University in Bulgaria. He has more than 30 years of experience in areas as computer science, quality management and information systems. He graduated Mathematics from Sofia University "St. Kliment Ohridski" in 1979. He completed his PhD thesis "Computer Aided Evaluation of Machine Reliability" in 1986. In 2009 he completes his D.Sc. thesis on "Quantitative Measures of Informing Quality". In ICTT "Informa" (1986-1993) Dr. Christozov was involved in establishing the national information network for technology transfer and conducted research in the areas of technologies assessment, integral quality measures and information systems for quality management. In these areas he was recognized as one of the leading experts in Bulgaria. Professor Christozov has more than 80 publications as separate volume, journal papers and papers in refereed proceedings. He is a founding member and fellow of Informing Science Institute and chair of Bulgarian Informing Science Society; and founding member of the Bulgarian Statistical Society.

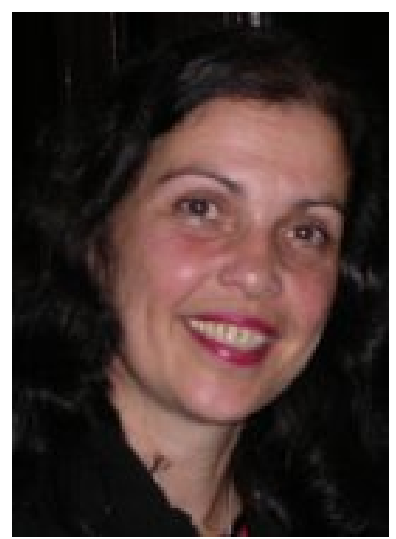

Dr. Stefanka Chukova is a Reader in Operations Research at the School of Mathematics, Statistics and Operation Research, Victoria University of Wellington, Private Bag 600, Wellington, New Zealand, e-mail: schukova@msor.vuw.ac.nz. She has a PhD in Mathematics (concentration in Probability and Statistics) from University of Sofia, Sofia, Bulgaria. Her research interests are in applied stochastic models, warranty analysis, reliability and queuing. She has more than 80 publications and has presented papers at national and international conferences. Stefanka is an elected member of ISI. 


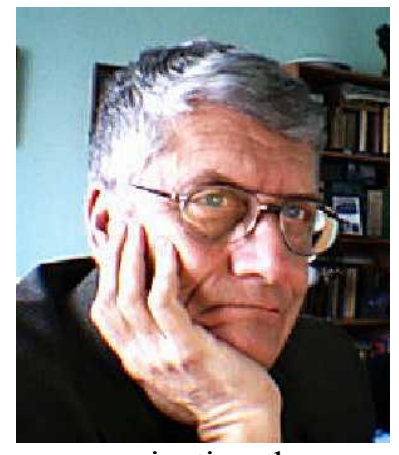

Dr. Plamen Mateev is Associate Professor and Supervisor of Statistical laboratory at the Department "Probability, Operation Research, Statistics", in Sofia University "St.Kliment Ohridski", Faculty of Mathematics and Informatics, Bulgaria, 1164 Sofia, 5, J. Boucher Str., e-mail: pmat@fmi.uni-sofia.bg.

He is a fellow of the Institute of Mathematics and Informatics of the Bulgarian Academy of Sciences.

His MSc in Mathematical Statistics is from Sofia University and his $\mathrm{PhD}$ is from Moscow State University. The research interests are in communication theory, applied statistics, statistical software and applications. He has published nearly 100 papers in scientific journals and conference proceedings. He was the Chair of Bulgarian Statistical Society and a member of ENBIS, IBS and a founding member of the Bulgarian Informing Science Society. 